\title{
Erratum to: Migrasomes: the knowns, the known unknowns and the unknown unknowns: a personal perspective
}

\author{
$\mathrm{Li} \mathrm{Yu}^{*}$
}

The State Key Laboratory of Membrane Biology, Tsinghua University-Peking University Joint Centre for Life Sciences, Beijing Frontier Research Center for Biological Structure, School of life Sciences, Beijing, China

Received December 7, 2020; published online December 22, 2020

Erratum to: Sci China Life Sci 2021, 64:162-166, https://doi.org/10.1007/s11427-020-1827-8

Citation: Yu, L. (2021). Erratum to: Migrasomes: the knowns, the known unknowns and the unknown unknowns: a personal perspective. Sci China Life Sci 64, 494. https://doi.org/10.1007/s11427-020-1864-3

The article "Migrasomes: the knowns, the known unknowns and the unknown unknowns: a personal perspective" written by $\mathrm{Li} \mathrm{Yu}$, was originally published Online First without Open Access. After publication online first, the author decided to opt for Open Choice and to make the article an Open Access publication. Therefore, the copyright of the article has been changed to (C) The Author(s) 2020 and the article is forthwith distributed under the terms of the Creative Commons Attribution 4.0 International License (http://creativecommons.org/licenses/by/4.0/), which permits use, duplication, adaptation, distribution and reproduction in any medium or format, as long as you give appropriate credit to the original author(s) and the source, provide a link to the Creative Commons license, and indicate if changes were made.

The original article has been corrected.

The online version of the original article can be found at https://doi.org/10.1007/s11427-020-1827-8

*Corresponding author (email: liyulab@tsinghua.edu.cn) 